\title{
A RARE CASE OF DESMOPLASTIC FIBROMA OF ULNA
}

Indudhara P. B ${ }^{1}$, Patil Pratima Shivagonda르. Ajeet Singh ${ }^{3}$

\section{HOW TO CITE THIS ARTICLE:}

Indudhara P. B, Patil Pratima Shivagonda, Ajeet Singh "A Rare Case of Desmoplastic Fibroma of Ulna". Journal of Evolution of Medical and Dental Sciences 2014; Vol. 3, Issue 32, August 04; Page: 8726-8728,

DOI: $10.14260 /$ jemds/2014/3113

ABSTRACT: Desmoplastic fibroma is an extremely rare locally aggressive primary bone tumor. It is a slowly progressive tumor commonly seen in mandible, femur, and pelvis. Rare in ulna. A young female of 18 years presented with swelling of right forearm. X ray showed lytic lesion with sclerotic margins mimicking soap bubble appearance. En bloc excisional biopsy was done. A histological diagnosis of Desmoplastic fibroma was made.

KEYWORDS: Fibroma, Desmoplastic, Ulna, Rare.

INTRODUCTION: Only 14 examples of desmoplastic fibroma are recorded in Mayo clinic files ${ }^{1}$. Paul Bohm and others reported only 191 cases. $^{2}$ The most common locations are the pelvis and long bones. ${ }^{1}$ Pain and swelling are the usual symptoms. Because of its rarity in ulna, this case is presented with review of literature.

CASE REPORT: 16 year old female presented with complaints of swelling in the distal right forearm. One year back, she had been operated for the same swelling at the local hospital. On examination, swelling was diffuse measuring around $3 \mathrm{~cm} \times 2.5 \mathrm{~cm}$, firm, non-mobile with surgical scar over skin. X ray showed expansile, oval lesion with well-defined sclerotic margins with thinned out cortex and intra lesional trabeculae giving lobulated appearance which is described as soap bubble appearance.

An en bloc excisional biopsy was done and sent for histopathological examination.

PATHOLOGICAL EXAMINATION: Grossly, grey white and grey brown soft tissue mass with bony attachment was received. On microscopy multiple sections studied show variable cellularity with moderate to abundant collagen. The tumor cells are spindle shaped fibroblasts arranged in fascicles (Fig. 1) and occasional whorls. The cells are uniform, benign looking and surrounded by collagenous matrix (Fig. 2). At the periphery of the tumor, focal infiltration of cancellous bone is seen.

DISCUSSION: Jaffé was the first to describe desmoplastic fibroma in 1958 and distinguish it from fibrosarcoma. As early as 1935, Cappell reported on a case of desmoplastic fibroma of the fibula but called it an endosteal fibroma. A desmoplastic fibroma of the jaw was first mentioned in 1965 (Griffith and Irby). ${ }^{3}$

It represents $0.06 \%$ of all osseous tumors and $0.3 \%$ of benign osseous tumors. It occurs during first three decades of life in over $75 \%$ of cases with an equal male and female preponderance. Pain and swelling or more rarely pathological fractures are the most frequent presenting symptoms. ${ }^{4}$

It can occur in any site in skeleton but is most common in the mandible or in the long bones. ${ }^{5}$

The mandible, femur, pelvis radius and tibia are the most common reported sites, although every bone of the peripheral skeleton can be affected. The desmoplastic fibroma is a slowly progressing locally invasive tumor characterized by a production of the collagen fibres by its tumor 
cells. A sarcomatoid transformation is unusual. The average delay for recurrence is about three years according to Bohm. ${ }^{4}$

Desmoplastic fibroma is mostly located centrally in the metadiaphysis of the tubular bones around knee followed by humerus and radius. It frequently has an aggressive appearance presenting as lytic expansile lesion. The lesion may have internal trabeculation and sclerotic margin. The hall mark of desmoplastic fibroma on M R Imaging is intermediate to low signal intensity on fluid sensitive sequences because of the high collagen content of fibrous component. ${ }^{6}$

It has been reported that intralesional surgical procedures such as curettages have high rate of recurrences, which has been estimated as between $50 \%$ and $72 \%$. Extralesional resection procedures seem to give better results with only a $5 \%$ recurrence. Thus en bloc resection is recommended. 4

CONCLUSION: Desmoplastic fibroma is a rare tumor occurring in ulna. It is a locally aggressive benign tumor with high rate of recurrence. Histological evaluation is important and should be considered as a differential diagnosis for swelling in the distal forearm. Wide resection or en bloc resection of the tumor is favored.

\section{REFERENCES:}

1. Inwards C Y, Unni K K. Sternberg's Diagnostic Surgical Pathology. 5th Edition. Lippincott Williams \& Wilkins; 2010. Chapter 8, Bone tumours; p. 237-279.

2. Bohm P, Krober S, Greschniok A, Laniado M, Kaiserling E. Desmoplastic Fibroma of the Bone. A Report of Two Patients, Review of the Literature, and Therapeutic Implications. Cancer. 1996 September 1; 78 (5):1011-1023.

3. Joachim, Remagen W, Spiessl B, Uehlinger E. Atlas of Tumors of the Facial Skeleton. Berlin Heidelberg: Springer; 1986. Odontogenic and Nonodontogenic Tumors; p. 135- 136.

4. Rouchya R, Courvoisiera A, Wimsey S, Bourgeoisa E, Burronic B, Griffeta J. Desmoplastic fibroma of the ilium. International Journal of Surgery Case Reports. 2013 July 17; 4: 875- 878.

5. Urresola A. Desmoplastic fibroma of bone: a report of two cases. Radiologia.2007 May 01; 49 (3): 205-10.

6. Motamedi K, Seeger L L. Benign Bone Tumors. Radiologic Clinics of North America. 2011 November; 49 (6): 1115-1134.

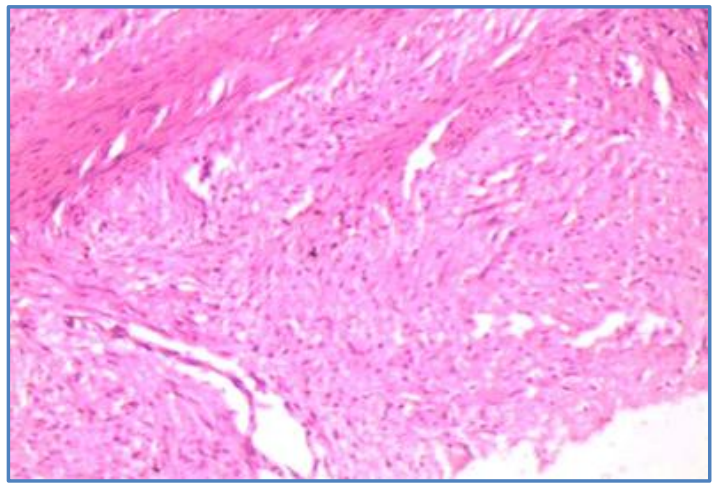

Fig. 1: Desmoplastic Fibroma showing small fibroblasts and collagen fibres 10X. H\&E stain 


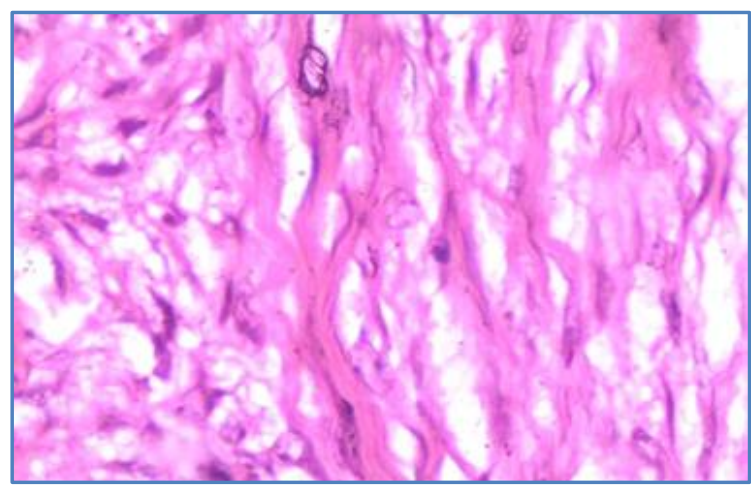

\section{Fig. 2: Desmoplastic Fibroma: Cells with oval nuclei and merge with intercellular collagen. 40 X. H \& E stain}

\section{AUTHORS:}

1. Indudhara P. B.

2. Patil Pratima Shivagonda

3. Ajeet Singh

\section{PARTICULARS OF CONTRIBUTORS:}

1. Assistant Professor, Department of Pathology, Subbaiah Institute of Medical Sciences, Shimoga.

2. Assistant Professor, Department of Pathology, SDM College of Medical Sciences, Dharwad.

3. Senior Resident, Department of Orthopedics. Lady Hardinge Medical College, New Delhi.

\section{NAME ADDRESS EMAIL ID OF THE} CORRESPONDING AUTHOR:

Dr. Indudhara P. B,

Assistant Professor,

Department of Pathology,

Subbaiah Institute of Medical Sciences,

Shimoga.

Email: indudharapb@gmail.com

Date of Submission: 15/07/2014.

Date of Peer Review: 16/07/2014.

Date of Acceptance: 26/07/2014.

Date of Publishing: 01/08/2014. 